\title{
Use of hemostatic powder (Hemospray) in the man- agement of refractory gastric variceal hemorrhage
}

Hemospray (Cook Medical, WinstonSalem, North Carolina, USA) is a novel powder licensed for endoscopic treatment of nonvariceal upper gastrointestinal bleeding (UGIB). It acts by forming a barrier over the bleeding site, increasing local concentration of clotting factors and activating the intrinsic clotting cascade [1]. Hemospray has been shown to be effective in peptic ulcer bleeding and other nonvariceal sources of UGIB [2-5]. We report its use in the management of gastric variceal bleeding refractory to injection of Histoacryl ( $n$-butyl cyanoacrylate; Braun Medical, Sheffield, UK), acting as a bridge towards a transjugular intrahepatic portosystemic shunt (TIPS) procedure.

A 37-year-old man presented with hematemesis. Endoscopy revealed bleeding gastric fundal varices (isolated type 1 gastric varices; $\bullet$ Fig. 1). These were injected using a mixture of Histoacryl and Lipiodol (iodized oil; Guerbet, Aulnay-sous-Bois, France). Immediate hemostasis was not obtained, so a further $1.2 \mathrm{ml}$ of this mixture was applied ( $\bullet$ Fig.2). However, bleeding continued ( $\bullet$ Fig. 3 ), therefore a decision was made to apply Hemospray, resulting in immediate hemostasis ( $\bullet$ Fig. 4). A TIPS for prevention of variceal rebleeding was performed 4 days later.

The recommended endoscopic therapy of bleeding gastric varices is injection of Histoacryl or thrombin. If this is unsuccessful, emergency TIPS procedure is indicated; however, in many centers the availability of emergency TIPS insertion is variable.

Theoretical concerns exist regarding embolization of Hemospray when treating variceal bleeding, due to the pressurized delivery system and the numerous shunts in these patients. Our patient had no complications of Hemospray application, and no embolization of the powder was detected clinically or on subsequent imaging.

In view of the large variceal size and multiple feeding vessels often found in gastric varices, it is unlikely that Hemospray would provide definitive treatment for

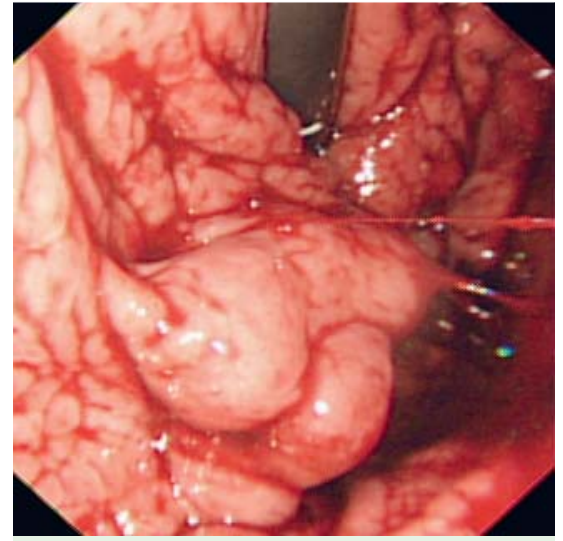

Fig. 1 Bleeding gastric varix in a 37-year-old man: before therapy.

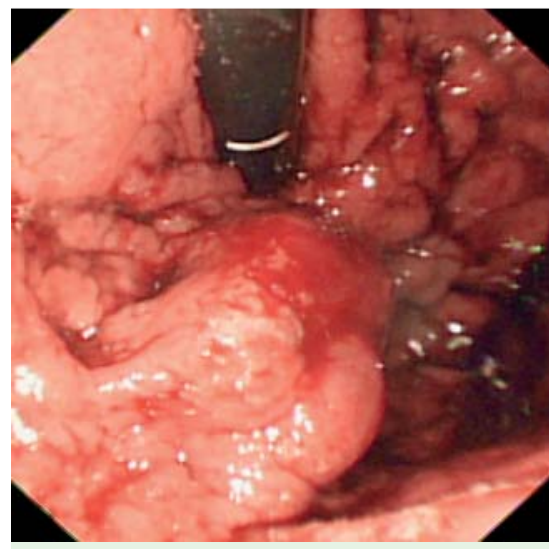

Fig.3 Gastric varix with ongoing bleeding despite two separate Histoacryl injections.

bleeding from this source. However, it may offer endoscopists an alternative therapeutic strategy for patients with bleeding uncontrolled by Histoacryl or thrombin injection, and in selected patients, provide a bridge towards TIPS insertion.

\section{Endoscopy_UCTN_Code_TTT_1AO_2AD}

Competing interests: Drs. A. J. Stanley and L. A. Smith have both received hospitality from Cook Medical. Dr. A. J. Morris has received speaker's fees and hospitality from Cook Medical.

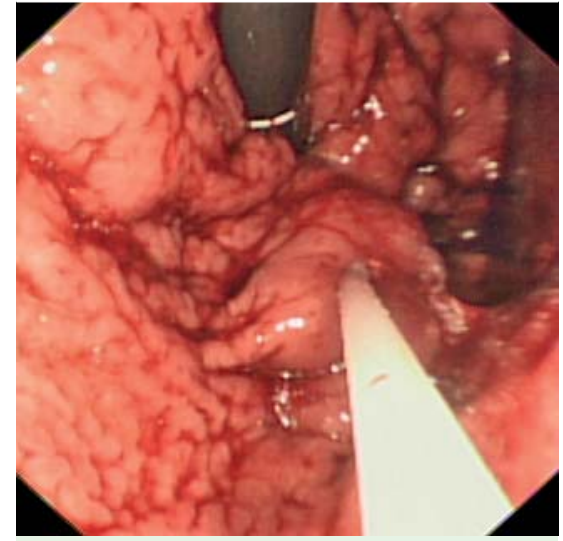

Fig.2 Injection of Histoacryl into gastric varix.

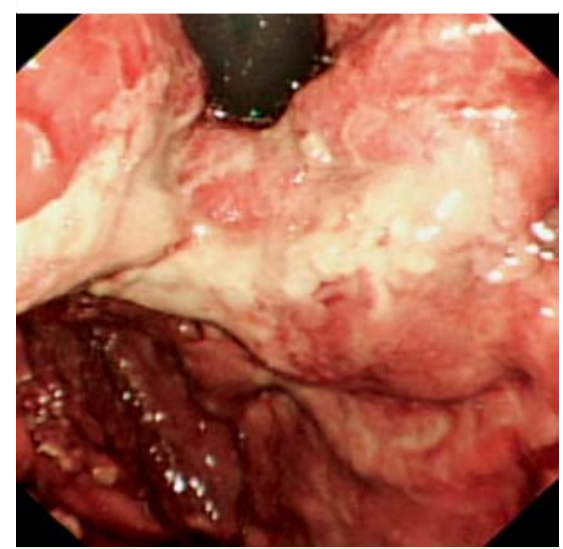

Fig.4 Gastric varix after application of Hemospray.

\section{A. J. Stanley, L. A. Smith, A. J. Morris}

Gastrointestinal Unit, Glasgow Royal Infirmary, Glasgow, UK

\section{References}

1 Holster IL, De Maat MP, Ducharme R et al. In vitro examination of the effects of the hemostatic powder (hemospray) on coagulation and thrombus formation in humans. Gastrointest Endosc 2012; 75: AB240

2 Giday SA, Kim Y, Krishnamurty DM et al. Long-term randomized controlled trial of a novel nanopowder hemostatic agent (TC-325) for control of severe arterial upper gastrointestinal bleeding in a porcine model. Endoscopy 2011; 4: 296-299

3 Sung JJ, Luo $D, W u J C$ et al. Early clinical experience of the safety and effectiveness of Hemospray in achieving hemostasis in patients with acute peptic ulcer bleeding. Endoscopy 2011; 43: $291-295$ 
4 Chen YI, Barkun AN, Soulellis C et al. Use of the endoscopically applied hemostatic powder TC-325 in cancer-related upper Gl hemorrhage: preliminary experience (with video). Gastrointest Endosc 2012; 75: $1278-1281$

5 Smith LA, Stanley AJ, Morris AJ. Hemospray for non-variceal upper gastrointestinal bleeding: results of the SEAL dataset (survey to evaluate the application of hemospray in the luminal tract). Gut 2012; 61: A61 - A62
Bibliography

Dol http://dx.doi.org/

10.1055/s-0032-1326258

Endoscopy 2013; 45: E86-E87

(c) Georg Thieme Verlag KG

Stuttgart · New York

ISSN 0013-726X
Corresponding author

\section{A. J. Stanley, MD}

Gastrointestinal Unit

Glasgow Royal Infirmary

Glasgow

G4 OSF

UK

Fax: +44-141-2115131

Adrian.stanley@ggc.scot.nhs.uk 